\title{
XXXIV. On the chemical formula of the nitroprussides
}

\section{John Kyd}

To cite this article: John Kyd (1850) XXXIV. On the chemical formula of the nitroprussides, Philosophical Magazine Series 3, 37:250, 289-291, DOI: 10.1080/14786445008646601

To link to this article: http://dx.doi.org/10.1080/14786445008646601

曲 Published online: 30 Apr 2009.

Submit your article to this journal \lceil

Џlll Article views: 4

Q View related articles $\sqsubset$ 


\section{[ 289 ]}

XXXIII. On a Geometrical Theorem. ByWilliam Spojtiswoode, M.A., of Balliol College, Oxford $*$. TF three cones of the second order, having a common ver1 tex, cut one another two and two in at least three straight lines, and if in each cone there be inscribed a hexahedral angle, such that each of the nine straight lines of intersection shall be a common edge of two hexahedral angles; then, adopting a former notation, the equations to the three cones may be written thus :-

$$
\begin{aligned}
& \mathrm{S}\left(\mathrm{V} \cdot \mathrm{V} \lambda_{1} \lambda_{2} \cdot \mathrm{V} \mu_{2} \nu_{1}, V \cdot V \mu_{1} \mu_{2} \cdot V \nu_{2} \lambda_{1} \cdot V \cdot V v_{1} \nu_{2} \cdot V \lambda_{2} \mu_{1}\right)=0 \\
& \left.S\left(V . V \lambda_{2} \lambda \cdot V \mu v_{2} \cdot V: V \mu_{22} \mu, V \nu \lambda_{2} \cdot V \cdot V \nu_{2} \nu, V \lambda \mu_{2}\right)=0\right\} \text {, } \\
& \mathrm{S}\left(\mathrm{V} \cdot \mathrm{V} \lambda \lambda_{1} \cdot \mathrm{V} \mu_{1} \nu, \mathrm{V} \cdot \mathrm{V}_{\mu \mu_{1}} \cdot V v_{1} \lambda, \mathrm{V} \cdot V_{\nu \nu_{1}} \mathrm{~V} \cdot \lambda_{1} \mu\right)=0
\end{aligned}
$$

or

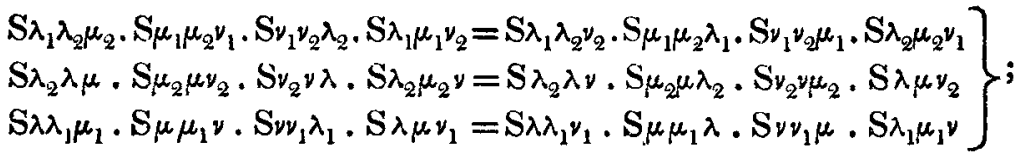

and if these be written thus,

the equation

$$
\mathrm{U}=\mathrm{W}, \quad \mathrm{U}_{1}=\mathrm{W}_{1}, \quad \mathrm{U}_{2}=\mathrm{W}_{2}, \ldots .
$$

$$
\mathrm{UU}_{1} \mathrm{U}_{2}=\mathrm{WW} \mathrm{W}_{2}
$$

will be of the fourth order in each of the vectors $\lambda_{1}, \lambda_{1}, \lambda_{2}, \ldots$, and will be satisfied when any of them $(e . g . v)$ is made to coincide successively with each of the others; $(4$.$) is consequently$ the equation of a cone of the fourth order, on which all the nine edges lie. Hence the following

Theonem. If three cones of the second order, having a common vertex, intersect one another troo and two, the nine lines of intersection (three being selected from each pair of cones) will lie on a cone of the fourth order.

Raigmore, Aug. 27, 1850.

XXXIV. On the Chemical Formula of the Nitraprussides. $B y$ Jorrn KYD†.

A $T$ the suggestion of Professor Will, I have made some $A$ experiments upon the nitroprussides recently described by Dr. Playfair, mainly with the view of testing the simple and elegant formula which Dr. Playfair considers as the probable one, although his experiments do not permit him to

* Communicated by the Author.

† From Liebig's Annalen, vol. lxxiv. p. 340.

Phil. Mag. S.3. Vol.37. No. 250. Oct. 1850. 
regard it as the expression of the analytical results. I selected for this purpose the soda salt, which is the most easily crystallized. The impure nitroprusside of sodium, which was obtained in solution by the saturation of the acid with carbonate of soda, was precipitated by the addition of sulphate of copper in the form of nitroprusside of copper; this was thoroughly washed with water, and lastly carefully decomposed by caustic soda. The solution of nitroprusside of sodium thus obtained was separated by filtration from the oxide of copper liberated, and evaporated at a gentle heat; large crystals were then obtained, which I submitted to analysis.

The iron and soda were estimated in the form of peroxide of iron and sulphate of soda, after the decomposition of the salt with concentrated sulphuric acid.

I. $0.531 \mathrm{grm}$. gave $0.1490 \mathrm{grm}$. of peroxide of iron and $0.2505 \mathrm{grm}$. of sulphate of soda.

II. $0.4 .71 \mathrm{grm}$. gave $0 \cdot 1330 \mathrm{grm}$. of peroxide of iron and $0.2223 \mathrm{grm}$. of sulphate of soda.

Regarding the combustions, the first was made with chromate of lead, the second with peroxide of copper and oxygen gas.

I. $0.5157 \mathrm{grm}$. gave $0.3937 \mathrm{grm}$. of carbonic acid and 0.0610 grm. of water.

II. $0.4394 \mathrm{grm}$. gave $0.3265 \mathrm{grm}$. of carbonic acid and $0.0526 \mathrm{grm}$. of water.

The determination of the nitrogen was made according to the method of Dumas : 0.298 grm. gave 74 cub. cent. of moist nitrogen at $57^{\circ} \mathrm{F}$., and with the barometer at $28^{\prime \prime}$.

I shall now compare these results with those of the composition calculated according to the simplest formula given by Playfair, and the mean of the same chemist's analyses of the soda salt obtained by the same method.

\begin{tabular}{|c|c|c|c|c|c|c|c|}
\hline & & & & & Found. & & Mean of \\
\hline & & Eq. & Calc. & I. & II. & Mean. & $\begin{array}{l}\text { Payrair s } \\
\text { analyses. }\end{array}$ \\
\hline Iron . & . & 2 & $19 \cdot 48$ & $19 \cdot 64$ & $19 \cdot 77$ & $19 \cdot 70$ & $19 \cdot 33$ \\
\hline Sodium & & 2 & $15 \cdot 9 \mathrm{~S}$ & $15 \cdot 4 \cdot 1$ & $15 \cdot 42$ & $15 \cdot 4.2$ & $15 \cdot 48$ \\
\hline Carbon & . & 10 & $20 \cdot 66$ & $20 \cdot 82$ & $20 \cdot 26$ & $20 \cdot 54$ & $20 \cdot 17$ \\
\hline Hydrogen & . & 4 & $1 \cdot 38$ & $1 \cdot 31$ & $1 \cdot 33$ & $1 \cdot 32$ & 1.53 \\
\hline Nitrogen & . & 6 & 28.93 & $29 \cdot 35$ & ... & $29 \cdot 35$ & $27 \cdot 78$ \\
\hline Oxygen & & 5 & $13 \cdot 77$ & ... & ... & $13 \cdot 66$ & \\
\hline & & & $00 \cdot 00$ & & & $100 \cdot 00$ & \\
\hline
\end{tabular}

Playfair's more complicated formula, $\mathrm{Fe}^{5} \mathrm{Cy}^{12}, 3 \mathrm{NO}, 5 \mathrm{Na}$ $+10 \mathrm{HO}$, requires in 100 parts, $19.33 \mathrm{Fe}, 16.02 \mathrm{Na}, 19.89 \mathrm{C}$, $1.38 \mathrm{H}$, and $29.00 \mathrm{~N}$. It is evident, therefore, that in regard to the arnount of soda and carbon, the analysis corresponds 
best with the more simple formula $\mathrm{Fe}^{2} \mathrm{Cy}^{5} \mathrm{NO}, 2 \mathrm{Na}+4 \mathrm{HO}$. The other elements, viz. the iron, the hydrogen and the nitrogen, when calculated according to both formulæ, so nearly coincide, that the difference cannot be ascertained with certainty by analysis. The amount of carbon appears to me decisive; because, as calculated according to both formule, it exhibits the greatest difference, and the quantity of carbon found is decidedly in favour of the more simple formula.

XXXV. On the Anomaly-Ruler; an Instrument to assist in the graphic representation of the place of a Gravitating Projectile in an Elliptic Orbit. By Wrlmam John Macquorn RANKINE, C.E., F.R.S.E., F.R.S.S.A. \&c.*

TT may sometimes be desirable, in lecturing on or in dis1 cussing the motions of comets, to possess the means of easily and rapidly laying down on a diagram, with as much accuracy as the scale of the drawing will permit, the places of such bodies in their elliptic orbits at given instants of time. The instrument which I shall now describe is intended to facilitate this operation.

It is simply a thin flat ruler, the form of which is represented by the shaded figure in the drawing, and which may be made of any convenient size.

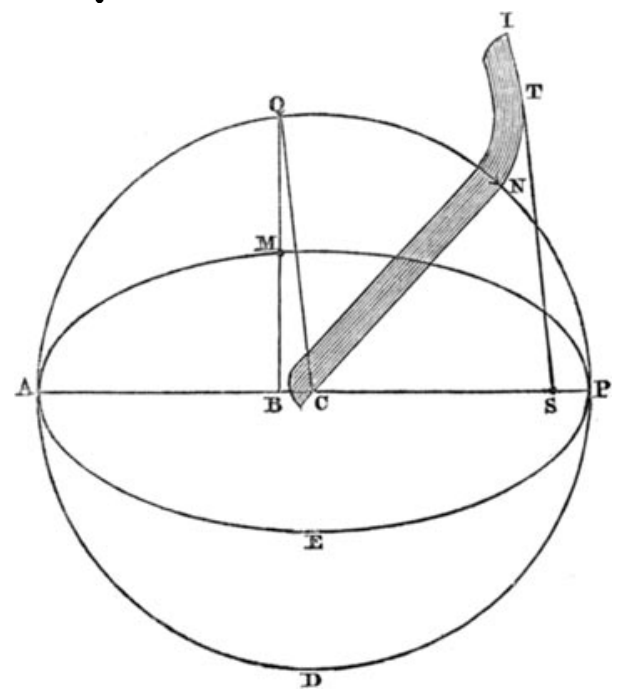

The fiducial edge, from $\mathrm{C}$ to $\mathrm{N}$, is straight. Those two points ought to be marked by fine transverse lines on both faces of the ruler. From $\mathrm{N}$ to $\mathrm{I}$ the fiducial edge has the

* Communicated by the Author. 